УДК 615.322:547.913(571)

\title{
ПОЛУЧЕНИЕ РАПСОВОГО МАСЛА ЭКСТРАКЦИЕЙ СВЕРХКРИТИЧЕСКИМ ДИОКСИДОМ УГЛЕРОДА
}

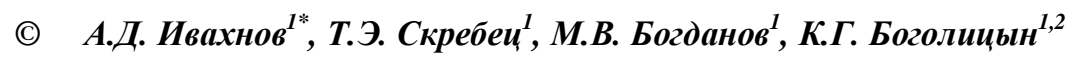 \\ ${ }^{1}$ Северный (Арктический) федеральный университет им. М.В. Ломоносова, \\ наб. Северной Двины, 17, Архангельск, 163002 (Россия), \\ e-mail: Ivahnov-tema@yandex.ru \\ ${ }^{2}$ Институт экологических проблем Севера УрО РАН Архангельск, \\ Набережная Северной Двины, 23, 163002 (Россия)
}

Выполнены сопоставительные исследования способов выделения масла из семян рапса (Canola) с применением в качестве растворителей гексана и сверхкритического диоксида углерода. Определены основные показатели качества получаемого масла и его жирнокислотный состав. Показано, что сверхкритический диоксид углерода может являться альтернативой традиционно используемым для этих целей углеводородам.

Ключевые слова: рапсовое масло, сверхкритическая флюидная экстракция, диоксид углерода, состав.

Работа выполнена при финансовой поддержке Министерства образования и науки РФ, ГК от 23.05.2011 №14.740.11.1019, и гранта РФФИ №11-03-12021-офu-м-2011.

\section{Введение}

Рапсовое масло является важным пищевым и техническим сырьем, которое характеризуется низким содержанием насыщенных жирных кислот, а его шрот - ценным источником белка [1].

Существует два основных способа получения рапсового масла: экстракция и отжим (холодный или горячий). Механический отжим масла связан с большими техническими трудностями, что привело к практически полному его вытеснению экстракционным способом. Вместе с тем последний обладает значительными недостатками, связанными прежде всего с применением токсичных углеводородных растворителей.

Реальной альтернативой существующему способу может стать сверхкритическая флюидная экстракция [2-8].

Ввиду уникальных свойств (низкие значения критических параметров - $\mathrm{T}_{\text {кр }} 304 \mathrm{~K}, \mathrm{P}_{\text {кр }} 7,4$ МПа, негорючесть и нетоксичность, хорошая растворяющая способность по отношению ко многим веществам) диоксид углерода является одним из основных растворителей, применяемых при реализации сверхкритических флюидных технологий.

\footnotetext{
Ивахнов Артём Дмитриевич - научный сотрудник центра коллективного пользования научным оборудованием «Арктика», кандидат химических наук, тел.: (8182) 21-89-48, e-mail: ivahnov-tema@yandex.ru Скребеи Татьяна Эдуардовна - профессор кафедры теоретической и прикладной химии, кандидат химических наук, тел.: (8182) 21-89-48, e-mail: t.skrebets@agtu.ru

Боголицын Константин Григорьевич - проректор по научной работе Северного (Арктического) федерального университета им. М.В. Ломоносова, директор Института экологических проблем Севера УрО РАН, доктор химических наук, профессор, тел.: (8182) 28-76-36, e-mail: bogolitsyn@ agtu.ru
}

Цель данной работы - изучение возможности выделения рапсового масла из семян рапса с использованием в качестве растворителя сверхкритического диоксида углерода.

\section{Объект и методы исследования}

В качестве объекта исследования были выбраны семена озимого рапса (Canola), отобранные в Вельском районе Архангельской области в 2012 г.

Для определения жирнокислотного состава полученных масел использован метод газожидкост-

\footnotetext{
* Автор, с которым следует вести переписку.
} 
ной хроматографии по ГОСТ 30418-96 с предварительным щелочным гидролизом и получением метиловых эфиров жирных кислот [11].

В виалу отбирали 0,1 мл рапсового масла, добавляли 1 мл гексан-эфирной смеси $1: 1$, затем вносили 0,5 мл 2 М КОН в метаноле, содержимое виалы интенсивно встряхивали в течение 2 мин. После 5минутного отстаивания отбирали верхний слой для газохроматографического анализа.

Количественное определение метиловых эфиров жирных кислот проводили, используя хроматограф Agilent Technologies 7820A GC System Maestro: колонка капиллярная: ZB-FFAP, 50 m ×0,32 mm×0,50 $\mu$ m, газ носитель - азот, детектор пламенно-ионизационный.

Определение содержания хлорофилла выполнено методом спектрометрии в видимой области спектра с использованием спектрофотометра Specord 250 Plus. Расчёт проведен относительно а-хлорофилла $(\varepsilon=91,2, \lambda=662 \mathrm{HM})[10]$.

\section{Результаты и обсуждение}

Определение массовой доли масел проводили по стандартной методике [9], основанной на экстракции сырья гексаном в аппарате Сокслета и последующей отгонке растворителя в вакууме. Полученный образец использован в качестве образца сравнения.

Сверхкритическая флюидная экстракция выполнена с использованием установки SFE 5000 производства Waters Corporation. Навеску сырья (79 г) помещали в автоклав объёмом 200 мл и обрабатывали диоксидом углерода при температуре $70{ }^{\circ} \mathrm{C}$, давлении 500 атм и при скорости потока 15 г/мин. Расход диоксида углерода составлял 50 кг/кг сырья. Высокий удельный расход диоксида углерода может быть компенсирован организацией его рецикла.

Определение физических (плотность, показатель преломления) и химических (кислотное, йодное, эфирное число, число омыления, перекисное число, содержание серы) показателей проводили по стандартным методикам [10].

Семена озимого рапса могут содержать до 36\% масла, в сыром масле могут содержаться различные растворённые компоненты (хлорофиллы, каротиноиды, гормоны) [12]. Классическим методом (экстракция гексаном) было установлено содержание масла в семенах 34,7\%. Методом сверхкритической флюидной экстракции (СКФЭ- $\left.\mathrm{CO}_{2}\right)$ с применением в качестве растворителя диоксида углерода было получено рапсовое масло с выходом $34 \%$.

Физико-химические и органолептические показатели полученных масел приведены в таблице 1 . По плотности и показателю преломления оба образца практически идентичны. Отсутствие запаха у образца, полученного экстракцией гексаном, закономерно ввиду того, что экстракт был упарен под вакуумом при удалении растворителя. Отсутствие запаха у масла, полученного сверхкритической флюидной экстракцией, объясняется одновременной его дезодорацией.

Таблица 1. Органолептические и физико-химические показатели рапсового масла

\begin{tabular}{|c|c|c|c|}
\hline \multirow[b]{2}{*}{ Наименование показателей } & \multicolumn{3}{|c|}{ Характеристика рапсового масла } \\
\hline & Экстракция гексаном & $\begin{array}{c}\text { Экстракция диоксидом } \\
\text { углерода }\end{array}$ & $\begin{array}{c}\text { Литературные данные } \\
\text { [12] }\end{array}$ \\
\hline Прозрачность & \multicolumn{2}{|c|}{ Прозрачно } & 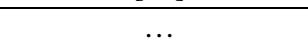 \\
\hline Цвет & Зеленовато-желтый & $\begin{array}{c}\text { Желтый с зеленоватым } \\
\text { оттенком }\end{array}$ & Бурый \\
\hline Запах & \multicolumn{2}{|c|}{ Отсутствует } & $\ldots$ \\
\hline Вкус & \multicolumn{2}{|c|}{ Свойственный рапсовому маслу } & $\ldots$ \\
\hline Содержание серы, \% & 8 & 2,5 & $6-30$ \\
\hline Плотность, г/дм ${ }^{3}$ & 912 & 913 & $911-918$ \\
\hline Показатель преломления & 1,475 & 1,476 & $1,472-1,476$ \\
\hline Кислотное число, мг NaOH/Г & 6,2 & 3,5 & $\ldots$ \\
\hline Число омыления, мг $\mathrm{NaOH} / \Gamma$ & 172 & 178 & $171-180$ \\
\hline Эфирное число, мг NaOH/г & 165,8 & 174,5 & $\ldots$ \\
\hline Йодное число г $\mathrm{I}_{2} / 100$ г & 98 & 104 & $95-106$ \\
\hline Перекисное число, 1 1/2О ммоль/кг & 1,22 & 0,36 & $\ldots$ \\
\hline Влага и летучие вещества, \% & 0,15 & 0,15 & $\ldots$ \\
\hline Содержание хлорофилла, г/100 г & 1,1 & 1,6 & $\ldots$ \\
\hline
\end{tabular}


Полученное методом сверхкритической флюидной экстракции масло семян рапса характеризуется значительно более низким кислотным числом, что указывает на меньшее содержание в нём свободных жирных кислот и более полное связывание жирных кислот в триглицериды, о чём также свидетельствует повышенное эфирное число.

Различие йодных чисел в 6 г $\mathrm{I}_{2} / 100$ г масла указывает на большую долю ненасыщенных жирных кислот в составе полученного масла. Низкая величина перекисного числа в масле, получаемом экстракцией с помощью сверхкритического $\mathrm{CO}_{2}$, вполне закономерна. Технология экстракции исключает контакт нагретого сырья или выделенного масла с кислородом окружающей среды. При экстракции с помощью аппарата Сокслета, по нашему мнению, данное взаимодействие имеет место, что и приводит к увеличению перекисного числа до 1,22 1/2О ммоль/кг. Влажность двух образцов масел оказалась на одинаковом уровне. Масло, получаемое методом сверхкритической флюидной экстракции, несколько обогащено хлорофиллом, что является положительным фактором при использовании его в пищевом производстве. По параметру «массовая доля серы» рапсовое масло, полученное методом СКФЭ-СО ${ }_{2}$, относится к маслу, пригодному для гидрирования в твердые жиры, в отличие от масла, получаемого экстракцией гексаном.

Хроматограммы метилированных жирных кислот рапсового масла представлены на рисунке. Порядковые номера пиков соответствуют номерам кислот, представленных в таблице 2. Жирнокислотный состав полученных масел приведен в таблице 2.

a)

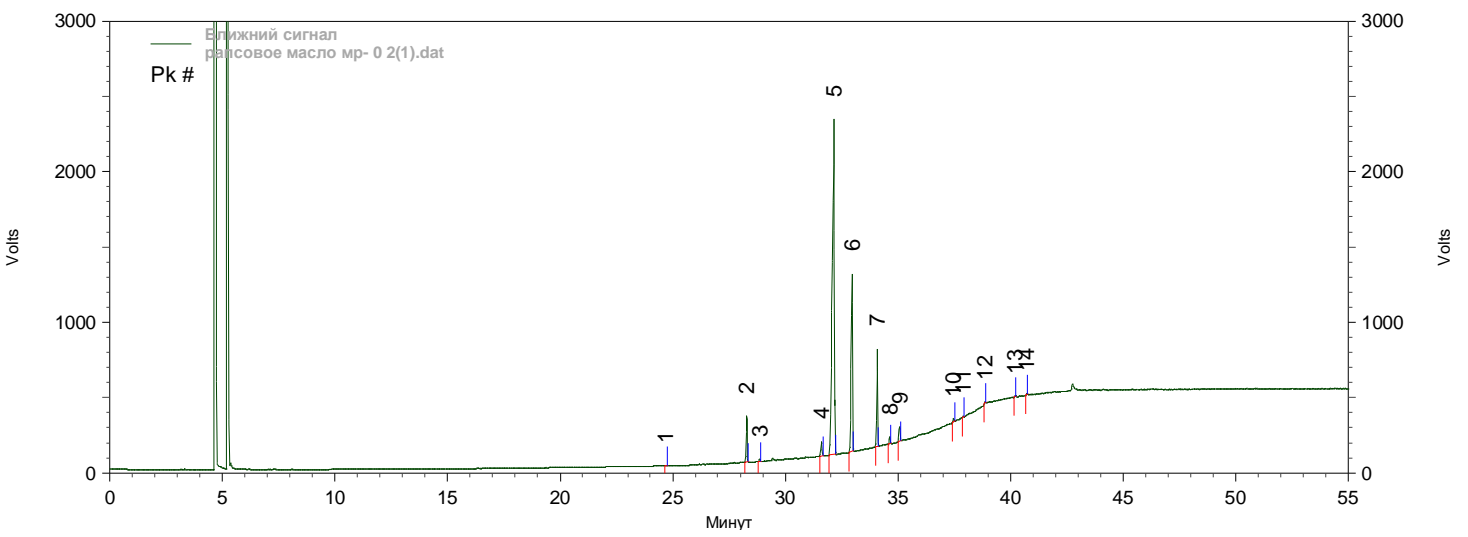

б)

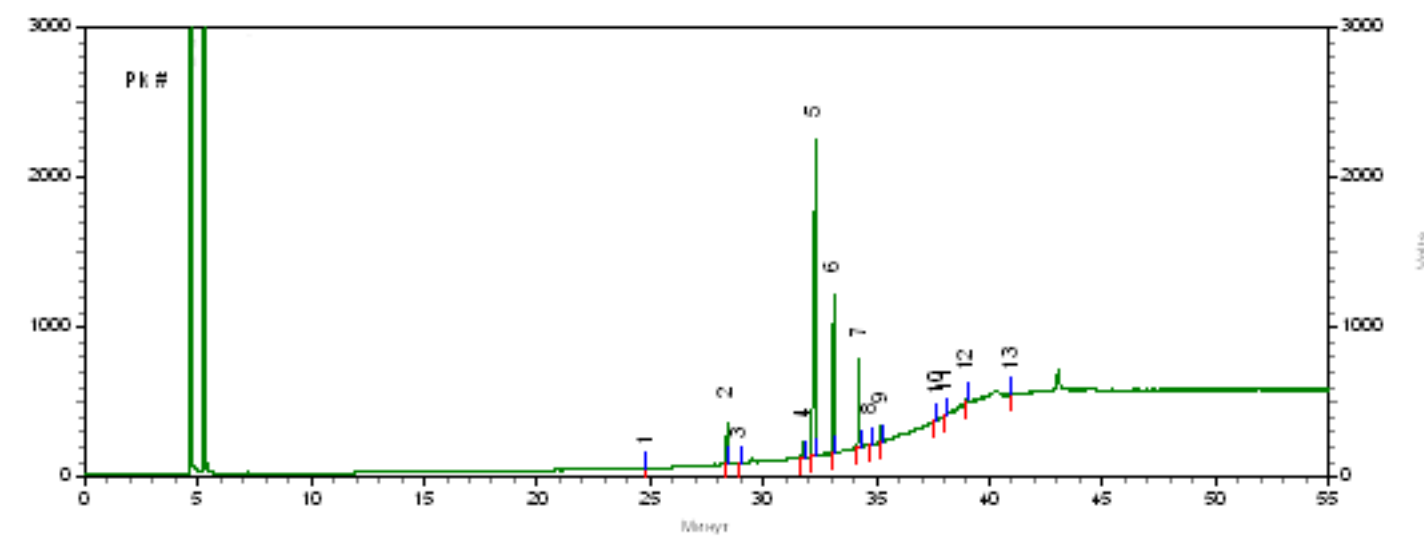

Хроматограмма метиловых эфиров жирных кислот рапсового масла, полученного экстракцией гексаном (а) и методом СКФЭ- $\mathrm{CO}_{2}$ (б)

Таблица 2. Жирнокислотный состав рапсового масла

\begin{tabular}{c|l|c|c|c}
\hline \multirow{2}{*}{ № } & Состав жирных кислот, & \multicolumn{3}{|c}{ Характеристика рапсового масла } \\
\cline { 3 - 5 } & \multicolumn{1}{|c|}{ Экстракция гексаном } & Экстракция диоксидом углерода & Литературные данные [13] \\
\hline 1 & 2 & 3 & 4 & 5 \\
\hline 1 & Миристиновая (14:0) & 0,045 & 0,042 & До 0,3 \\
2 & Пальмитиновая (16:0) & 4,29 & 3,99 & $2,5-6,5$ \\
3 & Пальмитолеиновая (16:1) & 0,20 & 0,22 & До 0,6 \\
4 & Стеариновая (18:0) & 1,91 & 1,78 & $0,8-2,5$ \\
5 & Олеиновая (18:1) & 62,91 & 62,70 & $50,0-65,0$ \\
\hline
\end{tabular}


Окончание таблицы 2

\begin{tabular}{c|l|c|c|c}
\hline 1 & \multicolumn{1}{|c|}{2} & 3 & 4 & 5 \\
\hline 6 & Линолевая (18:2) & 19,23 & 19,64 & $15,0-25,0$ \\
7 & Линоленовая (18:3) & 8,64 & 9,03 & $7,0-15,0$ \\
8 & Арахиновая (20:0) & 0,62 & 0,54 & $0,1-2,5$ \\
9 & Гондоиновая (20:1) & 1,36 & 1,32 & $0,1-4,0$ \\
10 & Бегеновая (22:0) & 0,31 & 0,27 & До 1,0 \\
11 & Эруковая (22:1) & 0,08 & 0,04 & До 5,0 \\
12 & Доказадиеновая (22:2) & 0,12 & 0,40 & До 0,5 \\
13 & Лигноцериновая (24:0) & 0,14 & 0 & До 0,2 \\
14 & Нервоновая (24:1) & 0,11 & 0,09 & $\ldots$ \\
\hline
\end{tabular}

Жирнокислотный состав полученных масел близок, однако масло, полученное методом СКФЭ-СО 2 , характеризуется значительно более низким содержанием эруковой кислоты и повышенным содержанием линоленовой кислоты, являющейся $\omega$-3-непредельной жирной кислотой, особенно ценной с диетической точки зрения.

\section{Bblводbl}

1. Показана возможность извлечения масла из семян рапса методом сверхкритической флюидной экстракции с использованием в качестве растворителя сверхкритического диоксида углерода.

2. Основное отличие масла, полученного методом СКФЭ- $\mathrm{CO}_{2}$, от масла, получаемого экстракцией гексаном, состоит в повышенной доле триглицерида при уменьшении доли свободных кислот.

Экспериментальная часть работы выполнена на оборудовании ЦКП НО «Арктика» (Северный (Арктический) федеральный университет имени М.В. Ломоносова) при финансовой поддержке Минобрнауки России».

\section{Список литературь}

1. Thobani M., Diosady L.L. Two-phase solvent extraction of canola // Journal American Oil Chemist's Society. 1997. Vol. 70. Pp. 207-214.

2. Illés V., Daood H.G., Perneczki L.S., Szokonya L., Then M. Extraction of coriander seed oil by CO2 and propane at super- and subcritical conditions // The Journal of Supercritical Fluids. 2000. Vol. 17. Pp. 177-186.

3. Hegel P.E., Zabaloy M.S., Mabe G.D.B., Pereda S., Brignole E.A.. Phase equilibrium engineering of the extraction of oils from seeds using carbon dioxide + propane solvent mixtures // The Journal of Supercritical Fluids. 2007. Vol. 42. Pp. 318-324.

4. Hamdan S., Daood H.G., Toth-Markus M., Illés V. Extraction of cardamom oil by supercritical carbon dioxide and sub-critical propane // The Journal of Supercritical Fluids 2008. Vol. 44. Pp. 25-30.

5. Freitas L.S., Oliveira J.V., Dariva C., Jacques R.A., Caramão E.B. Extraction of grape seed oil using compressed carbon dioxide and propane: extraction yields and characterization of free glycerol compounds // Journal of Agricultural and Food Chemistry. 2008. Vol. 56. Pp. 2558-2564.

6. Corso M.P., Fagundes-Klein M.R., Silva E.A., Cardozo-Filho L., Santos J.N., Freitas L.S., Dariva C. Extraction of sesame seed (Sesamun indicum L.) oil using compressed propane and supercritical carbon dioxide // The Journal of Supercritical Fluids. 2010. Vol. 52. Pp. 56-61.

7. Boutin O., Badens E. Extraction from oleaginous seeds using supercritical $\mathrm{CO}_{2}$ : experimental design and products quality // Journal of Food Engineering. 2009. Vol. 92. Pp. 396-402.

8. Sun M., Xu L., Saldanã M.D.A., Temelli F. Comparison of canola meals obtained with conventional methods and supercritical $\mathrm{CO}_{2}$ with and without ethanol // Journal American Oil Chemist's Society. 2008. Vol. 85. Pp. 667-675.

9. ГОСТ 13496.15-97. Корма, комбикорма, комбикормовое сырье. Методы определения содержания сырого жира.

10. Артюнян Н.С., Корнена Е.П., Мартовщук Е.В. Лабораторный практикум по химии жиров. СПб., 2004. 264 с.

11. ГОСТ 30418-96 Масла растительные. Метод определения жирнокислотного состава.

12. ГОСТ Р 53457-2009 Масло рапсовое. Технические условия.

13. Тютюнников Б.Н. Химия жиров. М., 1974. 260 с. 
Ivahnov A.D..$^{{ }^{*}}$, Skrebets T.E. ${ }^{l}$, Bogdanov M.V. ${ }^{1}$, Bogolitsyn K.G. ${ }^{1,2}$ RAPE OIL EXTRACTION WITH SUPERCRITICAL CARBON DIOXIDE

${ }^{I}$ Northern (Arctic) Federal University named after M.V. Lomonosov, Northern Dvina Emb., 17, Arkchangelsk, 163002 (Russia), e-mail: Ivahnov-tema@yandex.ru

${ }^{2}$ Institute of Invironmental problems of the North UD RAS, Northern Dvina Emb., 23, Arkchangelsk, 163060 (Russia)

Comparative researches of ways of allocation of oil from rape (Canola) seeds with application hexane and supercritical carbon dioxide as solvents were executed. The main indicators of quality of received oil and its fat acids structure were defined. It was shown that supercritical carbon dioxide can be alternative to hydrocarbons traditionally used for these purposes.

Keywords: rape oil, supercritical fluid extraction, carbon dioxide, structure.

\section{References}

1. Thobani M., Diosady L.L. Journal American Oil Chemist's Society, 1997, vol. 70, pp. 207-214.

2. Illés V., Daood H.G., Perneczki L.S., Szokonya L., Then M. The Journal of Supercritical Fluids, 2000, vol. 17, pp. 177-186.

3. Hegel P.E., Zabaloy M.S., Mabe G.D.B., Pereda S., Brignole E.A. The Journal of Supercritical Fluids, 2007, vol. 42, pp. 318-324.

4. Hamdan S., Daood H.G., Toth-Markus M., Illés V. The Journal of Supercritical Fluids, 2008, vol. 44, pp. 25-30.

5. Freitas L.S., Oliveira J.V., Dariva C., Jacques R.A., Caramão E.B. Journal of Agricultural and Food Chemistry, 2008, vol. 56, pp. 2558-2564.

6. Corso M.P., Fagundes-Klein M.R., Silva E.A., Cardozo-Filho L., Santos J.N., Freitas L.S., Dariva C. The Journal of Supercritical Fluids, 2010, vol. 52, pp. 56-61.

7. Boutin O., Badens E. Journal of Food Engineering, 2009, vol. 92, pp. 396-402.

8. Sun M., Xu L., Saldanã M.D.A., Temelli F. Journal American Oil Chemist's Society, 2008, vol. 85, pp. 667-675.

9. GOST 13496.15-97 Korma, kombikorma, kombikormovoe syr'e. Metody opredeleniia soderzhaniia syrogo zhira. [State standards 13496.15-97 Feed, mixed feeds and raw materials. Methods for determination of crude fat]. (in Russ.).

10. Artiunian N.S., Kornena E.P., Martovshchuk E.V. Laboratornyi praktikum po khimii zhirov. [Laboratory workshop on the chemistry of fats]. St. Petersburg, 2004, 264 p. (in Russ.).

11. GOST 30418-96 Masla rastitel'nye. Metod opredeleniia zhirnokislotnogo sostava. [State standards 30418-96 Vegetable oils. Method for determination of fatty acid composition]. (in Russ.).

12. ГОСТ Р 53457-2009 Масло рапсовое. Технические условия. [State standards R 53457-2009. Rapeseed oil. Specifications]. (in Russ.).

13. Tiutiunnikov B.N. Khimiia zhirov. [Chemistry of fats]. Moscow, 1974, 260 p. (in Russ.).

Received November 8, 2012

\footnotetext{
* Corresponding author.
} 
